\section{Magnetic fields and acute lymphoblastic leukemia in children: a systematic review of case-control studies}

\author{
Campos magnéticos e leucemia linfocítica aguda \\ em crianças: revisão sistemática de estudos \\ caso-controle
}

\author{
1 Faculdade de Saúde \\ Pública, Universidade de São \\ Paulo, São Paulo, Brasil. \\ 2 Associação Brasileira \\ de Compatibilidade \\ Eletromagnética, São Paulo, \\ Brasil. \\ Correspondence \\ D. M. Pelissari \\ Departamento de \\ Epidemiologia, Faculdade de \\ Saúde Pública, Universidade \\ de São Paulo. \\ Av. Dr. Arnaldo 715 \\ São Paulo, SP \\ 01246-904, Brasil. \\ danipelica@usp.br
}

\begin{abstract}
Leukemia incidence in children has increased worldwide in recent decades, particularly due to the rise in acute lymphoblastic leukemia. Studies have associated exposure to non-ionizing radiation generated by low frequency magnetic fields with childhood leukemia. The current article reviews the case-control studies published on this subject. Of 152 articles tracked in different databases, ten studies from North America, Asia, and Europe met the defined selection criteria, with patients diagnosed from 1960 to 2004. Methodological limitations were observed in these articles, including difficulties with the procedures for assessing exposure. An association may exist between exposure to low frequency magnetic fields and acute lymphoblastic leukemia in children, but this association is weak, preventing the observation of consistency in the findings. Future studies from a wider range of geographic regions should focus on the analysis of acute lymphoblastic leukemia, which is the subtype with the greatest impact on the increasing overall incidence of childhood leukemia.
\end{abstract}

Radiation Exposure; Lymphoid Leukemia; Child
Daniele Maria Pelissari 1 Flávio Eitor Barbieri 2 Victor Wünsch Filho ${ }^{1}$

\section{Introduction}

Leukemia is the most common malignant neoplasm in childhood, comprising about one-third of cancers in children under 14 years of age ${ }^{1}$. The most common subtype (approximately $80 \%$ ) is acute lymphoblastic leukemia (ALL) ${ }^{2}$. Studies in North America 3, Asia 4, and Europe 5 indicate stability in the overall incidence of malignant neoplasms in children, but an upward trend for leukemia. Subtype analysis of leukemias shows that the increase in these rates is due mainly to the increase in ALL. In Brazil, the leukemia incidence rates (41 and 36 per 1 million, respectively, for boys and girls) show a similar phenomenon 6 . Data from the Population Cancer Registry for the city of São Paulo, which has the longest historical series of cancer incidence in Brazil, show an increase in the incidence of lymphoid leukemias in children from 1969 to 20037.

Although part of this increase may be due to improvement in recording leukemia diagnosis, this does not entirely explain the increasing incidence of ALL. One hypothesis is that the trend results from factors related to modern lifestyle 7 , including intensive use of electricity.

Epidemiological studies on acute childhood leukemia have examined numerous possible risk factors with the aim of determining the disease etiology. A recent review ${ }^{8}$ only identified ionizing radiation as a risk factor for ALL, while other potential factors showed conflicting results. 
In 1979, Wertheimer \& Leeper 9 found a positive association between exposure to low frequency magnetic fields and leukemia and brain cancer in children younger than 19 years. Since then, the scientific literature has expanded on the possible health-related effects of exposure to magnetic fields. In addition to brain tumors and leukemia in children, the research has explored the association between exposure to low frequency magnetic fields and birth defects 10 and different types of cancer, like breast cancer in men 11, breast cancer in women 12 , lung cancer 13 , testis 11 , and prostate 14 , lymphomas, multiple myeloma, and melanoma 15. Much of the research in the last 20 years on magnetic fields and their effect on cancer has focused on childhood leukemia. In addition to dozens of case-control studies, there was one cohort study in Finland 16, two case-control studies nested in cohorts 17,18 , and two meta-analyses 19,20.

Based on these studies and particularly on the results of meta-analyses, the International Agency for Research on Cancer (IARC) 21 classified low frequency magnetic fields as class $2 \mathrm{~B}$, possibly carcinogenic to humans.

Low frequency magnetic fields (fields generated by $50 \mathrm{~Hz}$ or $60 \mathrm{~Hz}$ electric power generation, transmission, and distribution lines) display long waves, approximately $3,500 \mathrm{~km} 22$. These fields cross the human body without directly depositing any energy. In the environment, nonionizing radiation generated by $50 \mathrm{~Hz}$ or $60 \mathrm{~Hz}$ magnetic fields displays values of 0.01 to $0.2 \mu \mathrm{T}$ (microteslas, the measurement of intensity of magnetic fields, or density of the magnetic flows), but exposures greater than $0.3 \mu \mathrm{T}$ can occur in industrial settings 21 .

The main problem with case-control studies in this area of research is the evaluation and quantification of exposure to low frequency magnetic fields. The difficulty in obtaining precise data, adequately expressing the exposure to given individuals, derives from the retrospective nature of case-control studies, in addition to the complexity of characterizing sources of exposure and estimating the total effect from diverse sources 21 .

The methodology applied to the investigation of exposure to magnetic fields relates to the original proposal by Wertheimer \& Leeper 9, using the so-called "wire code" classification. The authors' point of departure was the configuration of electric power transmission lines, considering some aspects: (a) probable load in the transmission lines; (b) thickness of the wires; (c) location of the transformers; and (d) proximity of the homes to the power lines. Homes were clas- sified as either HCC (high current configuration) or LCC (low current configuration).

Others researchers subsequently introduced some refinements in the wire code system. Thus, Barnes et al. 23 reclassified the categories as: underground (UG), very low current configuration (VLCC), ordinary low current configuration (OLCC), ordinary high current configuration (OHCC), and very high current configuration (VHCC); and Kaune \& Savitz 24 as: low (LCC), medium (MCC), and high current configuration (HCC).

Savitz et al. ${ }^{25}$ quantified the magnetic fields using measurements from a dosimeter in the households' different rooms. Coleman et al. 26 evaluated exposure to magnetic fields considering the distance to the homes and type and voltage of transmission systems to estimate the magnetic field. Feychting \& Ahlbom 17 based their estimates on the distance between residences and power transmission equipment, and defined individuals living close to transmission towers as the population at risk.

Such studies have generally evaluated the risk of exposure to magnetic fields for leukemias as a whole. Few studies have specifically investigated ALL 25,27,28,29,30. Only two of these studies showed statistically significant associations with ALL 27,30. The others did not find statistically significant associations with either leukemias as a whole or ALL as a subgroup 25,28,29.

The aim of this article was to review the results of case-control studies that evaluated the possible association between exposure to nonionizing radiation generated by low frequency magnetic fields and incidence of ALL, the most common subtype of leukemia in children and the main subtype responsible for the increase in overall leukemia incidence in children in different regions of the world.

\section{Methods}

We tracked studies on the subject in three databases: MEDLINE (http://www.ncbi.nlm. nih.gov/pubmed, accessed on 13/Mar/2008), which includes 17 million publications indexed in the health sciences field since 1950, LILACS (http://bases.bireme.br/cgi-bin/ wxislind.exe/iah/cys/? IsisScript=iah/iah. xis\&base $=$ LILACS\&lang $=p$, accessed on 13/ Mar/2008), which includes the literature in Latin American and Caribbean countries 1982, with more than 445 thousand records, and in the Scientific Electronic Library Online (SciELO; http:/ / www.scielo.org/php/índex.php, accessed on 13/ Mar/2008), with some 170 thousand articles pub- 
lished in 545 periodicals in Latin America, Spain, and Portugal.

The main inclusion criterion was case-control studies on exposure to low frequency magnetic fields. We chose to analyze studies with the same design (case-control) as a way of reducing the heterogeneity between studies, and because case-control was the main methodological approach used to assess the effect of exposure to non-ionizing radiation from low frequency magnetic fields on incidence of ALL. As additional criteria, our review only included articles published in Spanish, English, or Portuguese; with a specific analysis of cases diagnosed with ALL or that included at least $50 \%$ of cases of ALL among all the leukemias in the series; and with cases and controls younger than 15 years.

In the MEDLINE database, the descriptor "electromagnetic fields" produced a list of 11,062 articles, reduced to 507 when the term "leukemia" was included. Addition of the term "power lines" narrowed the search to 60 articles. We chose to conduct a new search using the term "epidemiologic" rather than "power lines", and obtained a list with 92 articles. Thus, the two searches totaled 152 articles, of which nine were found on both lists. Therefore, from this database, a total of 143 articles were selected for review.

In the LILACS database, the descriptor "electromagnetic fields" produced a list of 80 articles. Addition of the term "leukemia" narrowed the list to three articles. No further key words were used in this situation. The three articles referred to the same study, with an ecological design. The same criteria as in the LILACS database were applied to the SciELO base, resulting in six articles.

The articles' abstracts were analyzed to verify whether they met the inclusion criteria. When the abstract failed to provide sufficient information to decide on its inclusion in the review, the article's full text was reviewed. Of the $152 \mathrm{ar}-$ ticles indexed in the three databases, only ten were selected for the present review, all from MEDLINE and published in English. The others failed to meet the predetermined inclusion criteria (Table 1).

\section{Results}

The selected articles included research conducted in countries of North America, Asia, and Europe from 1960 to 2004. The number of controls selected for each case varied from one to five. Table 2 summarizes the descriptive data from the ten selected studies. Four studies analyzed cancers in general, but with specific evaluations of exposure to low frequency magnetic fields and
ALL. Four others included all types of leukemia and evaluated ALL separately. Only two exclusively analyzed ALL. The number of cases of ALL analyzed in the studies varied from 22 to 1,331 .

Age of the case was adopted as the criterion for matching controls in all ten studies. In addition, nine studies matched controls in relation to cases by gender $17,18,25,27,28,29,30,31,32$, five by region of birth 18,25,28,30,31, and three by race $31,32,33$, while only one considered the power line rightof-way in which the case resided 17 and another considered socioeconomic status 32 .

Cases were selected from regional cancer registries $17,18,25,28$, cancer research groups $27,30,31,33$, or referral hospitals for cancer diagnosis and treatment 28,32. Population-based controls were selected by random telephone dialing 25,27,31,32, local residential registries 28,30 , or cohorts 17,18 . Hospital-based controls were only used by Feizi \& Arabi 32 . The study from the United Kingdom (UKCCSI) 29 selected cases and controls from the databases of the Family Health Service Authority and Health Board.

The selected studies used different approaches to evaluate exposure to low frequency magnetic fields. All the studies used two or more procedures to evaluate exposure (Table 3 ). Five studies adopted the wire code categorization, seven used dosimeter measurements of magnetic fields, four calculated estimates of magnetic fields, and six used distances from power lines. All ten studies adopted various adaptations of each method to evaluate exposure to magnetic fields, as described below.

\section{Wire Code System}

Table 4 shows the four studies 25,27,28,33 that adopted the wire code classification based on calculation of odds ratios (OR). Another study 31 evaluated exposure to magnetic fields based on the wire code classification, but in an unusual way in comparison to the other studies. Kleinerman et al. 31 distributed individuals according to wire code categories and strata of distances from homes to power lines. They found that $43.1 \%$ of subjects lived more than 40 meters from UG + VLCC lines, followed by OLCC lines (25.4\%) (data not shown in Table 4).

Different classifications from the wire code system were adopted, and some used more than one classification. Three studies $25,27,28$ used the categories proposed by Wertheimer \& Leeper 34 in their study on cancer in adults, three others 27,31,33 adopted the category proposed by Barnes et al. 23 , and three studies $27,28,33$ used the category proposed by Kaune \& Savitz 24 . 
Articles selected in the first phase of the database search.

\begin{tabular}{|c|c|}
\hline Literature databases and study characteristics & $\mathrm{n}$ \\
\hline MEDLINE & 143 \\
\hline Articles selected & 10 \\
\hline Articles not selected & 133 \\
\hline Other epidemiological designs (not case-control) and reviews & 92 \\
\hline Literature review & 38 \\
\hline Methodological discussion & 22 \\
\hline Commentary by editors or authors & 21 \\
\hline Meta-analysis & 5 \\
\hline Experimental & 6 \\
\hline Articles with sample populations older than 15 years & 13 \\
\hline Other neoplasms & 13 \\
\hline Other languages & 11 \\
\hline High frequency magnetic fields & 4 \\
\hline LILACS & 3 \\
\hline Articles selected & 0 \\
\hline Articles not selected & 3 \\
\hline Other epidemiological designs (not case-control) and reviews & 3 \\
\hline Ecological & 3 \\
\hline SciELO & 6 \\
\hline Articles selected & 0 \\
\hline Articles not selected & 6 \\
\hline Other epidemiological designs (not case-control) and reviews & 5 \\
\hline Methodological discussion & 2 \\
\hline Experimental & 2 \\
\hline Case study & 1 \\
\hline Articles with sample populations older than 15 years & 1 \\
\hline Total & 152 \\
\hline
\end{tabular}

Important risks, although not statistically significant, were observed by Savitz et al. 27 and McBride et al. 28. Protective associations were found by Linet et al. 33 and Green et al. 27. The studies that used the Wertheimer \& Leeper classification 34 did not find statistically significant associations $25,27,28$, but two showed a risk for leukemia 25,28 . Both the studies 27,33 that used the classification by Barnes et al. 23 and those 27,28,33 that used the classification proposed by Kaune \& Savitz 24 found non statistically significant risk (Table 4).

\section{Dosimeter measurement of magnetic fields}

Table 5 shows the results of studies that used dosimeter measurements to assess indoor residential exposure to magnetic fields.

Green et al. 27 and Kabuto et al. 30 found large, statistically significant associations with levels of exposure to magnetic fields greater than $0.15 \mu \mathrm{T}$ and $0.4 \mu \mathrm{T}$, respectively. The other studies also identified excess (but not statistically significant) risk $17,27,28,33$.

Linet et al. 33 conducted 24-hour measurements next to the child's bed and 30-second measurements in the different rooms and in the bedroom where the mother had slept during pregnancy. In each home, they calculated a summary of the levels of magnetic fields, based on the mean weights of the measurements in the rooms. The attributed weights were derived from the individual exposure and the estimated time spent by the child in each room, according to age. Tynes \& Haldorsen 18 conducted 24-hour measurements in the homes of children living close to $300 \mathrm{kV}$ lines. Green et al. 27 took spot measurements in various places indoors and outdoors. McBride et al. 28 assessed exposure to magnetic fields by individualized measurements, with the dosimeter placed next to the child for 48 hours, and for 24 hours in the bedroom where the child 
Table 2

Articles selected for the review.

\begin{tabular}{|c|c|c|c|c|c|c|c|}
\hline $\begin{array}{l}\text { Reference/Year of } \\
\text { publication }\end{array}$ & Country & $\begin{array}{l}\text { Period of } \\
\text { diagnosis }\end{array}$ & $\begin{array}{l}\text { Case/control } \\
\text { ratio }\end{array}$ & Cases & Leukemia & $\begin{array}{c}\text { Acute } \\
\text { lymphoblastic } \\
\text { leukemia }\end{array}$ & $\begin{array}{l}\text { Type of } \\
\text { cancer }\end{array}$ \\
\hline Savitz et al. 25/1988 & United States & 1976-1983 & $1: 1$ & 252 & 103 & 73 & Cancer * \\
\hline Feychting \& Ahlbom 17/1993 & Sweden & 1960-1985 & $1: 4$ & 142 & 39 & 22 & Cancer ** \\
\hline Linet et al. 33/1997 & United States & 1989-1994 & $1: 1$ & 638 & 638 & 638 & $\begin{array}{c}\text { Acute } \\
\text { lymphoblastic } \\
\text { leukemia }\end{array}$ \\
\hline Tynes \& Haldorsen 18/1997 & Norway & 1965-1989 & $1: 5$ & 532 & 148 & 98 & Cancer *** \\
\hline Green et al. 27/1999 & Canada & 1985-1993 & $1: 2$ & 189 & 189 & 159 & Leukemia \\
\hline McBride et al. 28/1999 & Canada & 1990-1994 & $1: 1$ & 399 & 399 & 351 & Leukemia \\
\hline UKCCSI 29/2000 & $\begin{array}{l}\text { United } \\
\text { Kingdom }\end{array}$ & 1991-1995 & $1: 1$ & 3,380 & 1,582 & 1,331 & Cancer\# \\
\hline Kleinerman et al. 31/2000 & United States & 1989-1993 & $1: 1$ & 405 & 405 & 405 & $\begin{array}{c}\text { Acute } \\
\text { lymphoblastic } \\
\text { leukemia }\end{array}$ \\
\hline Kabuto et al. 30/2006 & Japan & 1999-2001 & $1: 2$ & 312 & 312 & 251 & Leukemia \\
\hline Feizi \& Arabi 32/2007 & Iran & 1998-2004 & $1: 1$ & $60-59$ & 60 & 58 & Leukemia \\
\hline
\end{tabular}

UKCCSI: United Kingdom Childhood Cancer Study Investigators.

* Brain tumors, leukemia, lymphomas, soft tissue cancers, and others;

** Brain tumors, leukemia, lymphomas, Wilms tumor, and others;

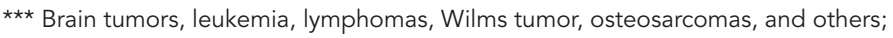

\# Brain tumors, leukemia, and others.

Table 3

Procedures used to evaluate exposure to low frequency magnetic fields in the selected articles.

\begin{tabular}{|c|c|c|c|c|}
\hline \multirow[t]{2}{*}{ Reference } & \multicolumn{4}{|c|}{ Type of evaluation } \\
\hline & Wire Codes & $\begin{array}{c}\text { Dosimeter } \\
\text { measurement }\end{array}$ & $\begin{array}{l}\text { Estimation of } \\
\text { magnetic fields }\end{array}$ & $\begin{array}{l}\text { Distance to power } \\
\text { lines }\end{array}$ \\
\hline Savitz et al. 25 & Yes & Yes & - & - \\
\hline Feychting \& Ahlbom 17 & - & Yes & Yes & Yes \\
\hline Linet et al. 33 & Yes & Yes & - & - \\
\hline Tynes \& Haldorsen 18 & - & Yes & Yes & Yes \\
\hline Green et al. 27 & Yes & Yes & - & - \\
\hline McBride et al. 28 & Yes & Yes & - & - \\
\hline UKCCSI 29 & - & - & Yes & Yes \\
\hline Kleinerman et al. 31 & Yes & - & - & Yes \\
\hline Kabuto et al. 30 & - & Yes & - & Yes \\
\hline Feizi \& Arabi 32 & - & - & Yes & Yes \\
\hline
\end{tabular}

UKCCSI: United Kingdom Childhood Cancer Study Investigators.

slept at the time of diagnosis. Kabuto et al. ${ }^{30}$ calculated the mean weekly magnetic field in the child's bedroom.

Savitz et al. 25 and Tynes \& Haldorsen 18 adopted a different approach from that used by the other studies shown in Table 5. Savitz et al. 25 measured the magnetic fields in different rooms in the homes of cases and controls on various days, at three distinct periods in the child's life: at birth, at the time of diagnosis, and two years after diagnosis. For each moment, the homes were classified according to electric power consumption (low versus high). They noted that children with ALL living in homes with low consumption 
Table 4

Leukemia risk and exposure to low frequency magnetic fields, evaluated by the wire code method.

\begin{tabular}{|c|c|c|c|}
\hline \multirow[t]{3}{*}{ Reference } & \multicolumn{3}{|c|}{ Wire code } \\
\hline & VH x UG (ref.) * & VHCC $x$ VLCC (ref.) ** & HCC $x$ LCC (ref.) *** \\
\hline & OR $(95 \% \mathrm{Cl})$ & OR $(95 \% \mathrm{Cl})$ & OR $(95 \% \mathrm{Cl})$ \\
\hline Savitz et al. 25 & $2.75(0.90-8.44)$ \# & - & - \\
\hline Linet et al. 33 & - & $0.88(0.48-1.63)$ \# & $1.04(0.65-1.66)$ \# \\
\hline Green et al. 27 & $0.90(0.33-2.46) \# \#$ & $0.89(0.33-2.44) \# \#$ & $0.88(0.44-1.75) \# \#$ \\
\hline McBride et al. 28 & $2.11(0.70-6.36) \#$ & - & $1.26(0.83-1.93) \# \#$ \\
\hline
\end{tabular}

OR (95\% Cl): odds ratio ( $95 \%$ confidence interval).

* Very high vs. Underground (reference category) 33 ;

** Very high current configuration vs. Very low current configuration (reference category) 20;

*** High current configuration vs. Low current configuration (reference category) 21;

\# Result for acute lymphoblastic leukemia;

\#\# Result for all leukemias.

Leukemia risk and exposure to low frequency magnetic fields, evaluated by dosimeter.

\begin{tabular}{|c|c|c|c|c|c|}
\hline \multirow[t]{3}{*}{ Reference } & \multicolumn{5}{|c|}{ Magnetic field measurements $(\mu \mathrm{T})$} \\
\hline & $\geq 0.13$ & $\geq 0.15$ & $\geq 0.15$ & $\geq 0.2$ & $\geq 0.4$ \\
\hline & OR $(95 \% \mathrm{Cl})$ & OR $(95 \% \mathrm{Cl})$ & OR $(95 \% \mathrm{Cl})$ & OR $(95 \% \mathrm{Cl})$ & OR $(95 \% \mathrm{Cl})$ \\
\hline Feyching \& Ahlbom 17 & - & - & - & $3.5(0.9-13.6) *, * \star$ & - \\
\hline Linet et al. 33 & - & - & - & $1.53(0.91-2.56) * * *$,\# & - \\
\hline Green et al. 27 & $2.83(0.83-9.62) * \star * * \#$ & $2.86(0.88-9.29) * \star \star, \# \#$ & $3.32(1.27-8.68) * * \star$,\#\#\# & - & - \\
\hline McBride et al. 28 & - & - & - & $1.19(0.77-1.84) * \star \star, \S$ & - \\
\hline Kabuto et al. 30 & - & - & - & - & $4.67(1.15-19.00) * * \star, \S \S$ \\
\hline
\end{tabular}

OR (95\%Cl): odds ratio (95\% confidence interval).

* Result for all leukemias;

** Spot measurement;

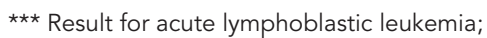

\# 24-hour measurement;

\#\# Indoor measurement;

\#\#\# Outdoor measurement;

§ 48-hour measurement;

$\S \S$ Weekly measurement.

and exposed to levels of magnetic fields $\geq 2.0 \mathrm{mG}$ (milligauss; $1 \mathrm{mG}=1 \mu \mathrm{T}$ ), as compared to the reference category $(<2.0 \mathrm{mG})$, showed an OR of 1.56 (95\%CI: 0.42-5.72). At the same exposure level, homes with high electric power consumption showed an OR of 1.05 (95\%CI: 0.34-3.26). Tynes \& Haldorsen 18 verified the time during which the child had been exposed to high-level 24-hour magnetic fields. Children with leukemia living up to 50 meters from the power line had been exposed to levels ranging from $0.4 \mu \mathrm{T}$ to $1.6 \mu \mathrm{T}$ for $75 \%$ of the 24 hours, while those living more than 150 meters from the power lines were exposed to levels less than $0.1 \mu \mathrm{T}$ for $83 \%$ of the time.

With the exception of Feychting \& Ahlbom 17 and Tynes \& Haldorsen 18, all the other studies analyzed ALL separately. 


\section{Estimated exposure to magnetic fields}

Table 6 shows the studies that evaluated exposure to magnetic fields by estimation. Statistically significant risk associations were found by Feyching \& Ahlbom 17 and Feizi \& Arabi 32 . Non-significant protective associations were found by Tynes \& Haldorsen 18 and the UKCCSI 29.

Feychting \& Ahlbom 17 estimated indoor exposure to magnetic fields produced by power lines in relation to all leukemias. Given the availability of year-round, 24-hour data on power line configurations and operations, it was possible to calculate the history of exposure to magnetic fields at the time of diagnosis using annual averages. The estimated measurements were validated using comparisons with spot measurements, in order to evaluate the precision of the estimates for magnetic fields.

The UKCCSI 29 applied a questionnaire on the power line configurations near residences that could generate magnetic fields greater than $0.1 \mu \mathrm{T}$. These data were collected for $11 \mathrm{kV}$ and $400 \mathrm{kV}$ lines (overhead and underground) located at a maximum of 400 meters from the home.

Tynes \& Haldorsen 18 calculated the history of exposure to non-ionizing radiation from low frequency magnetic fields based on the mean and maximum values in amperes for each year in which the individual lived near the line. Calculation of magnetic fields was validated by comparison of the values thus obtained with dosimeter measurements, using Pearson's coefficient (0.98) and Spearman's coefficient (0.86), leading the authors to conclude that estimation of magnetic fields was a good predictor of exposure. The authors calculated the risk measurement for all leukemias.

Feizi \& Arabi 32 calculated exposure to nonionizing radiation from low frequency magnetic fields based on the power lines' distance and configurations, done by an academic specialist working in a double-blind system, for all types of leukemia.

\section{Distance from power lines}

Table 7 shows the studies 17,18,30,32 on exposure to low frequency magnetic fields, considering the distance between homes and power lines. The studies calculated odds ratios and respective 95\% confidence intervals, and comparison of the strata closest to the power lines with the reference strata showed a statistically significant risk association in three studies 17,30,32.

The UKCCSI 29 and Kleinerman et al. 31 adopted a different statistical analysis from that of the other studies shown in Table 7.
The UKCCSI 29 calculated the mean distance between homes and power lines with different voltages (11-400kV). Next, the authors calculated the odds ratio for each line voltage. Distances from the power lines were calculated by the regional electric utility companies based on data provided by parents on a household history questionnaire. In cases of acute lymphoblastic leukemia, the authors found a mean distance of 95 meters from the $66 \mathrm{kV}$ power lines. Individuals living close to $66 \mathrm{kV}$ power lines showed an odds ratio of 2.76 (95\%CI: 0.76-10.0) compared to those living close to power lines with other voltages. Other tower voltages showed slight or no association (e.g., $400 \mathrm{kV}$ power lines): children living an average of 240 meters from $400 \mathrm{kV}$ lines showed an OR of 1.34 (95\%CI: 0.65-2.76) when compared to those not living close to power lines.

Kleinerman et al. 31 chose to analyze the distances between transmission and distribution power lines separately. They found an OR of 1.23 (95\%CI: 0.75 -2.03) for children living 24 to 40 meters from power lines. Living up to 23 meters from a transmission line showed an inverse association with incidence of ALL (OR: 0.57; 95\%CI: 0.15-2.13). Meanwhile, non-significant risk associations were observed for acute lymphoblastic leukemia in children living 15 to 23 meters (OR: 1.15; 95\%CI: $0.67-1.98$ ) and 24 to 40 meters (OR: 1.49; 95\%CI: 0.88-2.50) from distribution lines.

Kleinerman et al. 31 and Kabuto et al. 30 were the only authors that analyzed acute lymphoblastic leukemia separately, while the other authors analyzed leukemias as a whole.

\section{Discussion}

Epidemiological studies on the effect of exposure to non-ionizing radiation from low frequency magnetic fields on childhood leukemia are difficult to design, conduct, and interpret. The main difficulty is measurement of exposure to low frequency magnetic fields, since many sources generate such fields, with variations in distance and time. In addition, since the disease is rare, epidemiological studies are generally designed with a retrospective approach, and thus exposure is measured far from the actual time in which the potentially harmful exposure occurred.

In relation to evaluation of exposure using the wire code system, although the studies refer to use of the categories proposed by Wertheimer \& Leeper 9, Barners et al. 23, or Kaune \& Savitz ${ }^{24}$, in fact, given local electric system's characteristics, the authors introduced adaptations to classify households in strata with distinct exposure levels. 
Table 6

Leukemia risk and exposure to low frequency magnetic fields, evaluated by estimation.

\begin{tabular}{|c|c|c|c|c|c|}
\hline \multirow[t]{3}{*}{ Reference } & \multicolumn{5}{|c|}{ Estimated magnetic fields $(\mu \mathrm{T})$} \\
\hline & $\geq 0.14$ & $\geq 0.2$ & $\geq 0.3$ & $\geq 0.4$ & $\geq 0.45$ \\
\hline & OR (95\%Cl) & OR (95\%Cl) & OR $(95 \% \mathrm{Cl})$ & OR $(95 \% \mathrm{Cl})$ & OR $(95 \% \mathrm{Cl})$ \\
\hline Feyching \& Ahlbom 17 & - & $2.7(1.0-6.3) *$ & $3.8(1.4-9.3)$ * & - & - \\
\hline Tynes \& Haldorsen 18 & $0.8(0.3-2.4)$ * & - & - & - & - \\
\hline UKCCSI 29 & - & $0.51(0.11-2.33)$ ** & - & $0.33(0.04-2.72)$ ** & - \\
\hline Feizi \& Arabi 32 & - & - & - & - & $3.60(1.11-12.39)$ * \\
\hline
\end{tabular}

UKCCSI: United Kingdom Childhood Cancer Study Investigators; OR (95\%Cl): odds ratio (95\% confidence interval).

* Result for all leukemias;

** Result for acute lymphoblastic leukemia.

Table 7

Leukemia risk and exposure to low frequency magnetic fields, evaluated according to distance between homes and power lines.

\begin{tabular}{|c|c|c|c|}
\hline \multirow[t]{3}{*}{ Reference } & \multicolumn{3}{|c|}{ Distance $(\mathrm{m})$} \\
\hline & $\leq \mathbf{5 0}$ & $51-100$ & $\leq \mathbf{5 0 0}$ \\
\hline & OR $(95 \% \mathrm{Cl})$ & OR $(95 \% \mathrm{Cl})$ & OR $(95 \% \mathrm{Cl})$ \\
\hline Feyching \& Ahlbom 17 & $2.9(1.0-7.3)$ * & $1.1(0.4-2.7)$ * & - \\
\hline Tynes \& Haldorsen 18 & $0.6(0.3-1.3)$ * & $1.4(0.8-2.6)$ * & - \\
\hline Kabuto et al. 30 & $3.06(1.31-7.13) * *$ & $1.61(0.88-2.95)$ ** & - \\
\hline Feizi \& Arabi 32 & - & - & $8.76(1.74-58.40)$ * \\
\hline
\end{tabular}

OR (95\% Cl): odds ratio ( $95 \%$ confidence interval).

* Result for all leukemias;

** Result for acute lymphoblastic leukemia.

Following the development of various instruments to measure magnetic fields, the studies began to include dosimetry, considering different exposure levels and measurement times. The exposure levels assumed by the different studies as risky for leukemia in children ranged widely, from $0.03 \mu \mathrm{T}$ to $4 \mu \mathrm{T}$.

The studies adopted different measurement times in the child's bedroom: 24 hours 18,28,33, 48 hours 28 , or weekly 30 ; short measurement times $17,25,27,33$ in all the rooms in the home; short measurement times outdoors 27,33; and individual measurements 28 . Four studies used the mean measurement 17,27,28,30. However, other procedures were also used. Savitz et al. 25 divided the sample into two groups, based on electric power consumption, and then assigned the values obtained during the measurements. Linet et al. 33 assigned specific weights to the measurements in the household's rooms and in the child's bedroom, estimated by the child's age and the time spent in each room per day.

To estimate the magnetic field, Feychting \& Ahlbom 17 used data on distance between voltage towers and homes of cases and controls, height and distance between towers, distance and order of phases, and the power line load. The UK study 29 used data on distance between power lines and homes of cases and controls, as well as data on type of high-voltage towers, phase, and load. Feizi \& Arabi 32 calculated exposure to nonionizing radiation from low frequency magnetic fields based on power line distance and configuration, such as: voltage, mean electric power load, frequency, and phase. In situations where two towers were located close to the home, Feychting \& Ahlbom 17 chose the closest, while the UKCCSI 29 calculated the towers' combined al- 
terations to estimate the resulting magnetic field.

Studies that evaluated magnetic field exposure based on the distance between residences and power lines also used different methodological approaches. Besides considering potentially risky exposure strata ranging from 2331 to 500 meters 32 , the instruments also varied. Distance was calculated using maps 17,31, GPS (Global Positioning System) 30 , laser beam 30 , and tape measure 32

The studies' evaluation strategies depended on factors like data availability and characteristics of the local power system, making the comparison of results complex. Although measurement of exposure to non-ionizing radiation from low frequency magnetic fields remains limited and is still a challenge for epidemiology 35 , the evaluation procedures have made clear strides since research on this subject began.

The rarity of both the disease itself and prevalence of exposure at potentially risky levels hinders the elaboration of prospective studies, which are expensive and scarcely feasible in such a situation. According to Kheifets \& Shimkhada 35 , in addition to the difficulties in evaluating exposure to low frequency magnetic fields, which can lead to classification errors for individual exposure, the risk associations obtained in these studies may be due to chance, selection bias, or even lack of knowledge concerning other potential risks for the disease. The role of these issues in distorting the results of casecontrol studies on exposure to non-ionizing radiation from low frequency magnetic fields and childhood leukemia remains immeasurable.

Selection bias occurs when the participation rate differs between cases and controls in an epidemiological study, and participation depends on the type of target exposure 37 . The studies reviewed here reported participation rates ranging from 33 to $79 \%$. Studies that conducted indoor residential measurements showed a lower participation rate than those that adopted other approaches to evaluate exposure to magnetic fields. McBride et al. 28 reported that they only succeeded in measuring the magnetic fields for half of the initially selected control population.

When participation rates are available for cases and controls, the rate is obviously higher among cases as compared to controls. For example, Kleinerman et al. 31 obtained $90 \%$ participation for cases and $64 \%$ for controls. Ahlbom et al. 20 highlighted that selection bias may have contributed at least partially to the excess risk found in studies with pooled analysis.

Evaluation of exposure using the wire code system had the advantage of remaining relatively stable over the years, besides dispensing with the study subjects' participation, decreasing the odds of selection bias due to refusal to participate in the study, or to recall bias 36 . In studies where exposure to magnetic fields was measured based on the distance between homes and power lines or calculation of the magnetic field based on power line configuration, selection and recall biases are also reduced. Still, these forms of evaluation do not consider other sources of exposure, like electric appliances. Meanwhile, studies that used dosimeters to measure non-ionizing radiation from low frequency magnetic fields consider all the indoor residential sources of such radiation, but are subject to selection bias.

Prevalence of exposure to non-ionizing radiation from low frequency magnetic fields equal to or greater than $0.3 \mu \mathrm{T}$ is very low in the population, thus hindering reliable estimates of the effect of magnetic fields. Greenland et al. 19 called attention to the rarity of childhood exposure to low frequency magnetic fields greater than $0.3 \mu \mathrm{T}$ in the studies they analyzed.

Even in more recent studies with larger samples, few individuals among cases and controls were exposed to what were considered risky levels. In the UKCCSI study ${ }^{29}$, which included 1,331 cases of acute lymphoblastic leukemia and 3,390 controls, only two cases and 11 controls were exposed to levels greater than $0.2 \mu \mathrm{T}$.

Small samples can lead to underestimation of risk, thus preventing the differentiation between major and slight (or even absent) risk 35 . To minimize the effects of small samples, pooled analyses of data from different studies have been performed. Greenland et al. 19 and Ahlbom et al. 20, using this strategy, showed results with statistically significant excess risk of childhood leukemia from exposure to low frequency magnetic fields.

In addition to difficulties with measurement, another major challenge for such epidemiological studies has been the proper classification of individuals concerning exposure to non-ionizing radiation generated by low frequency magnetic fields. Errors in measurement or even estimates of magnetic fields were perceptible in all the studies, varying considerably between them. The procedures used for calibration and maintenance of dosimeters were rarely reported.

Another factor that can lead to classification bias for exposure is measurement of the magnetic field in a different home from that in which the child was exposed during the period prior to or at diagnosis. That is, when residential mobility is not controlled, classification bias is certain to occur. Using diverse procedures, the studies analyzed here sought to control for residential 
mobility of cases and controls. Some excluded individuals that changed addresses 25,27,30, others evaluated exposure to magnetic fields in different residences than their current home, including residences visited by the mother during the pregnancy, or the home in which the child lived at the time of diagnosis $17,18,28$. Finally, some authors stipulated a reliable time for the subject to live in the home in order to be eligible for measurement of magnetic fields $30,31,32,33$.

Confounding variables that are not completely controlled can also be considered as alternative explanations for the associations observed in case-control studies between exposure to non-ionizing radiation from low frequency magnetic fields and childhood leukemia 19. However, limited knowledge on the causes of leukemia in children hinders the identification of potential confounding variables. In the studies reviewed here, different variables were adjusted in the statistical models: air pollution 17 , viral infections 28 , exposure to chemical substances 27,28, and birth characteristics 30 . Most studies adopted socioeconomic status as a confounding variable. In order to be considered confounders, these variables had to exert an effect on both the target exposure and the disease 37 . Kheifets \& Shimkhada 35 found that although some of these variables have already been associated with leukemia, none of them could actually be considered a confounder.

In short, limitations like the small number of observations, precarious knowledge on risk factors for acute lymphoblastic leukemia, and especially methodological difficulties in assessing exposure to non-ionizing radiation from low frequency magnetic fields are seen in most of the studies analyzed here. Such factors may interfere in the results and may have contributed, to a greater or lesser degree, to the variability in the findings from the various studies. However, the methodological rigor in evaluating exposure has obviously improved, especially due to the strides obtained with the use of instruments for measuring magnetic fields and specific and portable geoprocessing.

The results of these epidemiological studies lead one to consider the possible existence of an association between exposure to non-ionizing radiation from low frequency magnetic fields and acute lymphoblastic leukemia in children, but the association is weak, thus preventing one from observing consistency in the results. Based on these findings, it would not be prudent to accept the hypothesis that the increasing incidence of acute lymphoblastic leukemia in different regions of the world can be explained by the growing use of electric energy and children's increasing exposure to non-ionizing radiation generated by low frequency magnetic fields. The case-control studies evaluated here were all conducted in countries in the Northern Hemisphere. Studies on this issue should be performed in other areas of the world in order to obtain a more comprehensive view of the possible effects of non-ionizing radiation generated by low frequency magnetic fields on acute lymphoblastic leukemia. The studies should focus on the analysis of acute lymphoblastic leukemia, since it is the subtype with the greatest share of the observed increase in childhood leukemia. Subsequently, these studies should be included in pooled analyses, allowing a larger number of observations coming from different regions of the world. 


\section{Resumo}

A incidência de leucemias em crianças tem aumentado nas últimas décadas no mundo, com influência predominante da leucemia linfocítica aguda, principal subtipo em crianças. Estudos têm relacionado a exposição às radiações não-ionizantes geradas pelos campos magnéticos de baixa freqüência com leucemia infantil. Neste artigo foram revisados os estudos casocontrole publicados sobre essa questão. Dos 152 artigos localizados em diferentes bases de dados, dez estudos da América do Norte, Ásia e Europa preencheram os critérios de seleção, comportando pacientes diagnosticados entre 1960 e 2004. Algumas limitações metodológicas foram observadas como dificuldades nos procedimentos de avaliação da exposição. É possível a existência de associação entre exposição a campos magnéticos de baixa freqüência e leucemia linfocítica aguda em crianças, porém, a força desta associação é tênue, impedindo observar consistência entre os resultados. Futuros estudos, com maior diversidade de regiões, deveriam concentrar-se na análise da leucemia linfocítica aguda, pois é o subtipo com maior influência na incidência crescente da leucemia infantil.

Exposição a Radiação; Leucemia Linfóide; Criança

\section{References}

1. Petridou E, Trichopoulos D. Leukemias. In: Adami HO, Hunter D, Trichopoulos D, editors. Textbook of cancer epidemiology. New York: Oxford University Press; 2002. p. 556-72.

2. Hodgson S, Foulkes W, Eng C, Maher E. A practical guide to human cancer genetics. $3^{\text {rd }}$ Ed. New York: Cambridge University Press; 2007.

3. Linabery AM, Ross JA. Trends in childhood cancer incidence in the U.S. (1992-2004). Cancer 2008; 112(Pt 2):416-32.

4. Swaminathan R, Rama R, Shanta V. Childhood cancers in Chennai, India, 1990-2001: incidence and survival. Int J Cancer 2008; 122:2607-11.

5. Coebergh JWW, Reedijk AMJ, Vries E, Martos C, Jakab Z, Steliarova-Foucher E, et al. Leukemia incidence and survival in children and adolescents in Europe during 1978-1997. Report from the Automated Childhood Cancer Information System project. Eur J Cancer 2006; 42:2019-36.

\section{Contributors}

D. M. Pelissari contributed with the interpretation of the studies and elaboration and revision of the article. F. E. Barbieri critically revised the article. V. Wünsch Filho participated in the article's elaboration and revision.
6. Ferlay J, Bray F, Pisani P, Parkin DM. Cancer incidence, mortality and prevalence worldwide. Lyon: IARC Press; 2004. (IARC Cancer Base, 5).

7. Pelissari DM. Campos eletromagnéticos e leucemia linfocítica aguda em crianças residentes na Região Metropolitana de São Paulo [Masters Thesis]. São Paulo: Faculdade de Saúde Pública, Universidade de São Paulo; 2009.

8. Belson M, Kingsley B, Holmes A. Risk factors for acute leukemia in children: a review. Environ Health Perspect 2007; 115(Pt 1):138-45.

9. Wertheimer N, Leeper E. Electrical wiring configuration and childhood cancer. Am J Epidemiol 1979; 109:273-84.

10. Blaasaas KG, Tynes T, Lie RT. Risk of selected birth defects by maternal residence close to power lines during pregnancy. Occup Environ Med 2004; 61 (Pt 2):174-6. 
11. Stenlund G, Floderus B. Occupational exposure to magnetic fields in relation to male breast cancer and testicular cancers: a Swedish case-control study. Cancer Causes Control 1997; 8:184-91.

12. Kliukiene J, Tynes T, Andersen A. Residential and occupational exposures to $50-\mathrm{Hz}$ magnetic fields and breast cancer in women: a population-based study. Am J Epidemiol 2004; 159(Pt 9):852-61.

13. Savitz DA, Dufort V, Armstrong B, Thériault G. Lung cancer in relation to employment in the electrical utility industry and exposure to magnetic fields. Occup Environ Med 1997; 54:396-402.

14. Charles LE, Loomis D, Shy CM, Newman B, Millikan R, Nylander-French LA, et al. Electromagnetic fields, polychlorinated biphenyls, and prostate cancer mortality in electric utility workers. Am J Epidemiol 2003; 157:683-91.

15. Tynes T, Klaeboe L, Haldorsen T. Residential and occupational exposure to $50 \mathrm{~Hz}$ magnetic fields and malignant melanoma: a population based study. Occup Environ Med 2003; 60(Pt 5):343-7.

16. Verkasalo PK, Pukkala E, Hongstro MY, Valjus JE, Jarvinen PJ, Heikkila KV, et al. Risk of cancer in Finnish children living close to power lines. BMJ 1993; 307:895-9.

17. Feychting M, Ahlbom A. Magnetic fields and cancer in children residing near Swedish high-voltage power lines. Am J Epidemiol 1993; 138:467-81.

18. Tynes T, Haldorsen T. Electromagnetic fields and cancer in children residing near Norwegian highvoltage power lines. Am J Epidemiol 1997; 145 (Pt 3):219-26.

19. Greenland S, Sheppard AR, Kaune WT, Poole C, Kelsh MA. A pooled analysis of magnetic fields, wire codes, and childhood leukemia. Epidemiology 2000; 11:624-34.

20. Ahlbom A, Day N, Feychting M, Roman E, Skinner J, Docherty J, et al. A pooled analysis of magnetic fields and childhood leukaemia. Br J Cancer 2000; 83:692-8

21. International Agency for Research on Cancer. Static and extremely low-frequency electric and magnetic fields. Lyon: International Agency for Research on Cancer; 2002. (IARC Monographs on the Evaluation of the Carcinogenic Risks to Humans).

22. Savitz DA, Ahlbom A. Electromagnetic fields and radiofrequency radiation. In: Schottenfeld D, Fraumeni Jr. JF, editors. Cancer epidemiology and prevention. 3rd Ed. New York: Oxford University Press; 2006. p. 306-21.

23. Barnes F, Wachtel H, Savitz D, Fuller J. Use of wiring configuration and wiring codes for estimating externally generated electric and magnetic fields. Bioelectromagnetics 1989; 10:13-21.
24. Kaune WT, Savitz DA. Simplification of the Wertheimer-Leeper wire code. Bioelectromagnetics 1994; 15:275-82.

25. Savitz DA, Wachtel H, Barnes FA, John EM, Tvrdik JG. Case-control study of childhood cancer and exposure to $60-\mathrm{Hz}$ magnetic fields. Am J Epidemiol 1988; 128:21-38.

26. Coleman MP, Bell CMJ, Taylor H-L, Primic-Zakelj M. Leukemia and residence near electricity transmission equipment: a case-control study. Br J Cancer 1989; 60:793.

27. Green LM, Miller AB, Agnew DA, Greenberg ML, Li J, Villeneuve PJ, et al. Childhood leukemia and personal monitoring of residential exposures to electric and magnetic fields in Ontario, Canada. Cancer Causes Control 1999; 10:233-43.

28. McBride M, Gallagher R, Thériault H, Armstrong B, Tamaro S, Spinelli J, et al. Power-frequency electric and magnetic fields and risk of childhood leukemia in Canada. Am J Epidemiol 1999; 149:831-42.

29. United Kingdom Childhood Cancer Study Investigators. Childhood cancer and residential proximity to power lines. Br J Cancer 2000; 83(Pt 11):1573-80.

30. Kabuto M, Nitta H, Yamamoto S, Yamaguchi N, Akiba S, Honda Y, et al. Childhood leukemia and magnetic fields in Japan: a case-control study of childhood leukemia and residential power-frequency magnetic fields in Japan. Int J Cancer 2006; 119:643-50.

31. Kleinerman RA, Kaune WT, Hatch EE, Wacholder S, Linet MS, Robison LL, et al. Are children living near high-voltage power lines at increased risk of acute lymphoblastic leukemia? Am J Epidemiol 2000; 151:512-5.

32. Feizi AAHP, Arabi MA. Acute childhood leukemias and exposure to magnetic fields generated by high voltage overhead power lines - a risk factor in Iran. Asian Pac J Cancer Prev 2007; 8:69-72.

33. Linet M, Hatch E, Kleinermann R, Robison L, Kaune W, Friedman D, et al. Residential exposure to magnetic fields and acute lymphoblastic leukemia in children. N Engl J Med 1997; 337:1-7.

34. Wertheimer N, Leeper E. Adult cancer related to electrical wires near the home. Int J Epidemiol 1982; 11:345-55.

35. Kheifets L, Shimkhada R. Childhood leukemia and EMF: review of the epidemiologic evidence. Bioelectromagnetics 2005; Suppl 7:51-9.

36. World Health Organization. Extremely low frequency fields. Environmental Health Criteria, 238. http://www.who.int/peh-emf/publications/ elf_ehc/en/ (accessed on 23/Sep/2008).

37. Breslow NE, Day NE. Statistical methods in cancer research. The analysis of case-control studies. Lyon: International Agency for Research on Cancer; 1980. (IARC Scientific Publication).

Submitted on 30/Mar/2009

Final version resubmitted on 15/Jul/2009

Approved on 03/Aug/2009 